\title{
MARCAS DE UMA TRAVESSIA: ASPECTOS DE SELEÇÃO, TRADUÇÃO E PUBLICAÇÃO DE CONTOS DE MACHADO DE ASSIS EM INGLÊS
}

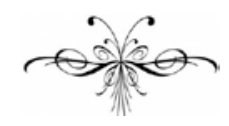

VÁLMI HATJE-FAGGION

Resumo: A produção literária de Joaquim Maria Machado de Assis (1839-1908) inclui em torno de duzentos contos, vários deles traduzidos para a língua inglesa e publicados em países anglófonos desde a primeira metade do século XX. Neste estudo é examinado o percurso de elaboração de quatro coletâneas de contos desse autor, quais sejam: Brazilian tales (1921); The psychiatrist and other stories, (1963); The devil's church and other stories (1977) e A chapter of hats and other stories (2008). O exame dessas quatro obras inclui questões relacionadas aos critérios de seleção dos contos, aos tradutores, aos paratextos e às editoras que publicaram essas obras ao longo de mais de nove décadas. O exame detalhado dessas coletâneas revela que elas são compostas pelos contos mais conhecidos do escritor, organizadas, traduzidas e retraduzidas quase sempre por acadêmicos e publicadas, primordialmente, por editoras universitárias.

Palavras-chave: Tradução de contos; Agentes institucionais; Paratextos; Questões editoriais.

\begin{abstract}
Joaquim Maria Machado de Assis' (1839-1908) literary production includes about two hundred short stories and a number of them have already been translated and published in Anglophone countries since the beginning of the $20^{\text {th }}$ century. This study examines the following four collections of short stories: Brazilian tales (1921); The psychiatrist and other stories (1963); The devil's church and other stories (1977), and A chapter of hats and other stories (2008). This study will consider issues related to selection, translators, paratexts and publishers which published those works during the last nine decades in English. The detailed comparative reading of those collections reveals that they are composed by the most well-known short stories, are translated and retranslated almost always by scholars and are published mainly by university publishers.
\end{abstract}

Keywords: Translation of short stories; Institutional agents; Paratexts; Editorial issues. 
o abordar questões inerentes ao processo tradutório, tais como as
relacionadas aos critérios de seleção da obra a ser traduzida, aos
tradutores e às editoras que publicam determinadas obras ao longo de diferentes períodos de tempo, parece importante examinar como as obras traduzidas são efetivamente formuladas e apresentadas em um novo polissistema cultural, deslocado no tempo e no espaço. Trata-se de verificar as razões que podem ser enumeradas para demonstrar porque uma dada obra de um dado escritor circula em tradução em um outro sistema literário e cultural.

Machado de Assis $^{1}$ é um dos escritores brasileiros que conheceu esse deslocamento em relação à sua obra literária por ela já ter sido traduzida para várias línguas, dentre elas a inglesa, principalmente seus romances e contos. E essa é justamente uma dimensão praticamente desconhecida nos estudos da obra de Machado de Assis. Muito pouco se tem escrito sobre a tradução de sua obra para o inglês (e inclusive para outras línguas). Assim, rastrear e sistematizar dados sobre essa faceta importante da obra do famoso escritor brasileiro tem por objetivo ampliar e divulgar a repercussão que sua obra vem experimentando pelo mundo há mais de nove décadas, e completar parte dessa lacuna.

Machado de Assis, considerado um dos pioneiros do conto no formato como é conhecido atualmente, conforme também destaca John Gledson (2007, p. 3) ${ }^{2}$,

\footnotetext{
${ }^{1}$ De acordo com BRAZILIAN AUTHORS TRANSLATED ABROAD (1994, p. 112-113), catálogo da Fundação Biblioteca Nacional com os dados sobre os autores brasileiros traduzidos para outras línguas, muitos dos contos de Machado de Assis já foram organizados em coletâneas, traduzidos e publicados em inglês, espanhol (Espanha, Argentina, México, Colômbia, Venezuela), holandês, alemão, italiano, sueco e francês. Os contos, Missa do Galo e Teoria do Medalhão traduzidos para o sueco e publicados em antologias suecas também são listados (p.226) na seção de autores publicados em antologias estrangeiras (Participation of Brazilian authors in foreign-published anthologies, collective works and literary journals).

$<$ http://www.itaucultural.org.br/aplicexternas/enciclopedia_lit/index.cfm?fuseaction=biografias_texto\& cd_verbete=4953\&cd_item=50>. Acesso em 07 de jul. de 2013. Esta página na internet lista apenas uma das coletâneas deste estudo de contos de Machado de Assis traduzidos para o inglês: The psychiatrist and other stories. Tradução de William L. Grossman e Helen Caldwell. Berkeley e Los Angeles: University of California Press, 1963; e London: Peter Owen, 1963. Nesta mesma página da internet, outra tradução de contos de Machado é citada: What went on the Baroness [contos] Tradução de Helen Caldwell. California: The Magpie Press, 1963. Ressalte-se que não tive acesso à cópia desta obra. Note-se que nesta página a tradução do romance Quincas Borba publicada pela Oxford University Press aparece com o nome do tradutor errado. O tradutor é Gregory Rabassa e não o mencionado, David T Haberley (que escreveu um metatexto para suplementar esta tradução).

<http://books.google.com.br/books/about/What_Went_on_at_the_Baroness.html?id=dPWNOgAACA AJ\&redir_esc=y>. Acesso em 07 de jul. de 2013. Esta página na internet lista a obra de Machado de Assis com os seguintes dados: What went on at the Baroness: a tale with a point. Tradução de Helen Caldwell. Santa Monica, California: The Magpie Press, 1963. 08 páginas. Illustration by Dulcie Luna. Printed in an edition of 100 copies (ilustração de Dulcie Luna. Impressa numa edição de 100 exemplares).

Há também a tradução de O alientista de Alfred Mac Adam publicada pela editora The Arion Press, San Francisco, Califórnia, 1998.

Apenas a segunda coletânea deste estudo aparece no Index da Unesco: <http://www.unesco.org/ xtrans/bsresult.aspx?a=machado+de+assis\&tr=schmitt>. Acesso em 20 de jul. de 2013.

2 "Machado is one of the great pioneers of the short story as we know it today." John Gledson, $<$ http://www.brazil.org.uk/events/machadodeassis_assets/lecturegledson.pdf $>$, p. 3. Acesso em 17 de outubro de 2009. For the last few months, I have been occupied with a project for the production of an anthology of some of Machado's stories - about 20 - for Bloomsbury. It will be published next year, and I hope will do something to boost his reputation, and encourage people to read him. The stories, in fact, seem to me an excellent way of doing this - Machado is one of the great pioneers of the short
} 
elaborou ao longo de sua carreira literária uma vasta obra que inclui cerca de duzentos contos. Um exame da história da tradução desses contos revela que vários deles foram traduzidos para a língua inglesa. Em geral cada conto foi traduzido uma única vez, mas há casos de contos que foram traduzidos mais de uma vez, tanto por tradutores americanos quanto britânicos, desde a década de vinte do século XX (1921).

Nesta pesquisa, quatro coletâneas de contos de Machado de Assis traduzidas para o inglês são examinadas: Brazilian tales, coletânea organizada e traduzida por Isaac Goldberg, e publicada pela International Pocket Library em Boston, EUA, em 1921; The psychiatrist and other stories, coletânea compilada e traduzida por William L. Grossman e Helen Caldwell, publicada pela University of California Press em Berkeley e Los Angeles, EUA, em 1963; The devil's church and other stories, coletânea organizada e traduzida por Jack Schmitt e Lorie Chieko Ishimatsu, e publicada simultaneamente pela University of Texas Press, em Austin e Londres, EUA e Inglaterra, respectivamente, em 1977; e, A chapter of hats and other stories, coletânea organizada e traduzida por John Gledson, e publicada pela Bloomsbury em Londres (Inglaterra), em Berlim (Alemanha) e em Nova Iorque (EUA), em 2008. ${ }^{3}$

O exame dessas quatro coletâneas inclui questões relacionadas aos critérios de seleção dos contos traduzidos (por que determinados contos compõem os volumes), aos tradutores (quem são, por que traduziram os contos, como os traduziram e organizaram os volumes) e às editoras (reimpressões, edições, prestígio, relevância).

Um aspecto relevante dos processos de tradução diz respeito aos metatextos que suplementam essas coletâneas. Eles incluem, por exemplo, a introdução elaborada pelo tradutor ou outros textos que fazem parte de estratégias de marketing e de comercialização, e que por isso constituem fontes de subsídios a respeito dos critérios de seleção dos contos traduzidos e publicados no mundo anglo-americano.

story as we know it today. He began to write his mature stories in about 1880, and in the next decade produced most of his best ones - choosing merely twenty is a hard task. This was the same time when two of the great masters, Maupassant and Chekhov, both of them much younger than Machado, began to give the genre a new intensity and identity. Today, they are seen as classics, and it is time Machado's best stories were seen in the same league.

${ }^{3}$ Um conjunto de contos de Machado traduzidos ao inglês foi publicado na Revista Translatio n. 1 (2011) da UFRGS. Os contos ‘A Chinela Turca' 'Um Conto de Escola', 'Um Homem Célebre’, ‘A Causa Secreta’ e 'Um Esqueleto’ foram vertidos para o inglês sob a coordenação de Rosalia Neumann Garcia. Em 2013, Garcia publicou em conjunto com Ian Alexander a obra A Machado de Assis anthology (new translations of Brazilian classics), uma coletânea de 17 contos de Machado traduzidos ao inglês.

Em 2013 foi publicada ainda a coletânea de oito contos The alienist and other stories of nineteenthcentury Brazil, organizada e traduzida por John Charles Chasteen e publicada em Indianapolis, EUA, pela editora Hackett: <http://www.hackettpublishing.com/latin-american-studies/the-alienist>. Os contos são os seguintes: To be twenty years old (Vinte anos! Vinte anos!), The education of a poser (Teoria do medalhão), The looking glass (O espelho), A singular occurrence (Singular ocorrência); Terpsichore (Terpsícore), Chapter on hats (Capítulo dos chapéus); Father against mother (Pai contra mãe) e The Alienist (O alienista). Como não tive acesso a cópias dessas obras por razões diversas, não são objeto de estudo integral neste artigo. Utilizo apenas os dados que consegui obter via páginas de editoras e outras páginas da internet. Essas coletâneas estão disponíveis para compra aqui: <http://www.amazon. com/Alienist-Other-Stories-Nineteenth-CenturyBrazil/dp/1603848525/> \& $<$ http://www.amazo n.com/Machado-Anthology-Translations-Brazilian-Classicsebook/dp/B005EHQJL8/>. Acesso em 29 de julho de 2013. 
Abordar a tradução de uma obra de dado escritor literário implica examinar aspectos e circunstâncias inerentes ao processo tradutório de forma mais ampla e abrangente. Um texto ficcional que é deslocado de um polissistema literário para outro parece indicar um interesse de uma cultura na produção literária de determinado autor estrangeiro. Além disso, ele é formulado e publicado sobretudo de acordo com certas expectativas dessa cultura receptora.

A tradução favorece a difusão de autores e obras, e pode ajudar a manter sua sobrevida. André Lefevere (1992, p. 13) enfatiza que se uma obra não for reescrita de uma forma ou outra, ela provavelmente não irá sobreviver por muito tempo após sua publicação. Por sua vez, Itamar Even-Zohar (1979) e Ria Vanderauwera (1985) destacam que obras são escolhidas para serem traduzidas levando em conta questões como o prestígio do autor e da obra na cultura de partida.

As diversas circunstâncias atreladas ao processo de tradução, influenciadas muitas vezes por razões comerciais e culturais, podem desempenhar um papel importante quando se decide quem vai ser traduzido, quais obras serão selecionadas, quando e com que impacto. Assim, para a concretização de uma tradução e sua publicação, concorrem, pois, diversos fatores implícitos e explícitos, sendo mobilizados vários participantes que atuam em diversas dimensões.

Vanderauwera (1985, p. 37) ${ }^{4}$, sugere haver dois tipos de tradução: a tradução de caráter embaixador, ou metaliterária, e a tradução voltada para o consumo. De acordo com a autora, ao se escolher uma tradução do tipo embaixadora, busca-se oferecer a estudantes da língua e/ou da literatura de partida material básico, tornando a literatura do texto de partida, seus autores principais, sua especificidade e excelência disponíveis a um público estrangeiro. Quanto à tradução voltada para o consumo (que visa se acomodar ao gosto e expectativas do leitor de chegada), os textos escolhidos e traduzidos são produzidos e apresentados de tal maneira que estejam adequados aos modos de edição de textos e às preferências literárias do leitor de chegada.

Ainda segundo Vanderauwera (1985, p. 37), as opções embaixadora e de consumo desempenham um papel fundamental na seleção de um romance a ser traduzido. Essas opções sustentam a formulação e a apresentação dos textos traduzidos para o inglês em proporções e maneiras diversas. O impacto varia de acordo com o projeto de tradução, o objetivo específico da tradução, o tipo de texto envolvido, o tradutor, o editor, e suas suposições sobre as expectativas do leitor. $\mathrm{O}$ objetivo de traduzir obras de Machado de Assis para o falante de língua inglesa poderia, por exemplo, envolver uma estratégia de tradução que privilegiasse as sutilezas e idiossincrasias de estilo do texto machadiano.

De acordo com Susan Bassnett ${ }^{5}$,

\footnotetext{
4 “Ambassadorial” or "metaliterary” works - as an ambassadorial choice, a translation is expected to provide students of the source language and or literature with basic material; it is intended to play an ambassadorial role, making the source text literature, its major authors, its specificity and excellence known to a foreign audience. As a 'consumer-oriented' choice (accommodating target taste and expectations) works are chosen for translation, and target texts produced and presented in such a way that they conform to the text editing routines and literary preferences of the target reader.

${ }^{5}$ Writing does not happen in a vacuum, it happens in a context and the process of translating texts from one cultural system into another is not a neutral, innocent, transparent activity. Translation is instead a highly charged, transgressive activity, and the politics of translation and translating deserve much greater attention than has been paid in the past.
} 
uma escritura não se processa num vácuo, mas ela ocorre num contexto e o processo de traduzir textos de um sistema cultural para outro não é uma atividade neutra, inocente e transparente. A tradução é uma atividade transgressora e marcada, e a política de tradução de como traduzir merece maior atenção do que foi dada no passado. (BASSNETT, 1991, p. 160-161)

Bassnett (1991, p. 161) ${ }^{6}$, ainda salienta que “a tradução teve papel fundamental na mudança cultural, e ao considerarmos a diacronia da prática da tradução nós podemos aprender bastante sobre a posição das culturas receptoras em relação às culturas do texto de partida.”

Para André Lefevere (1992, p. 13), o estudo de (re)traduções, por seu turno, pode, por exemplo, oferecer muitas informações sobre o processo de aculturação que ocorre na tradução assim como sobre as estratégias utilizadas, com graus de sucesso diversos. No entanto, para o autor é possível ir ainda mais além uma vez que muito da influência exercida por uma literatura em outra, ou em outras, tem sido na forma de reescritura - para além da tradução propriamente dita, como, antologia, historiografia e crítica. O modo como essas reescrituras são veiculadas pode, pois, revelar informações importantes do processo tradutório, ao passo que a configuração e a composição textual da tradução que é publicada pode ser examinada de forma que revele questões de ordem política, pessoal, econômica e cultural que podem estar mais ou menos explícitas.

Vanderauwera (1985) também destaca que várias opções e políticas podem ter um impacto na constituição do produto final, que em grande parte estão relacionadas a certas restrições impostas aos tradutores (bem como aos editores/revisores e às editoras). As decisões referentes ao tipo de literatura produzida para uma cultura de chegada, as preocupações financeiras da editora, os subsídios dados por instituições patrocinadoras ${ }^{7}$ para fomentar a literatura de partida em tradução são fatores relevantes no processo tradutório.

\footnotetext{
${ }^{6}$ Translation has played a fundamental role in cultural change, and as we consider the diachronics of translation practice we can learn a great deal about the position of receiving cultures in relation to source text cultures.

${ }^{7}$ Destaque-se o fomento financeiro dado para a tradução de obras brasileiras desde 2012 pelo projeto Revista Machado de Assis / Machado de Assis Magazine - literatura brasileira em tradução disponível no endereço www.machadodeassismagazine.bn.br. A Revista tem como objetivo estimular a difusão da literatura brasileira no exterior, é trimestral, em versão online, conta com duas edições impressas por ano. O Itamaraty / Ministério das Relações Exteriores do Brasil é responsável pela distribuição internacional; a Imprensa Oficial do Estado de São Paulo cuida da impressão; e o Itaú Cultural, que sugeriu o projeto à Fundação Biblioteca Nacional-FBN realiza a edição e alimenta o site da publicação. A revista tem circulação internacional, voltada, sobretudo para um público especializado, como agentes literários e editores. De acordo com Galeno Amorim (2012), presidente da Fundação Biblioteca Nacional-FBN, em carta de apresentação do projeto Revista Machado de Assis Literatura brasileira em tradução / Machado de Assis - Brazilian Literature in Translation, até 2020, “o Centro Internacional do Livro (CIL / International Book Center) da Biblioteca Nacional e do Ministério da Cultura irá investir mais de US\$ 30 milhões em bolsas de tradução, programas de residência para tradutores, participação em feiras de livros internacionais e promoção de escritores brasileiros no exterior.”. $<$ http://www.bn.br/portal/index.jsp?nu_padrao_apresentacao=25\&nu_item_conteudo=2120\&nu_pagin $\mathrm{a}=1>$ Acesso em novembro de 2012. [Galeno Amorim]
} 
O esquema téorico de análise descritiva de tradução literária de José Lambert e Hendrik Van Gorp (1985), organizado em quatro estágios ${ }^{8}$, é adotado neste estudo para respaldar a investigação dos fatores implícitos e explícitos envolvidos no processo de tradução de textos traduzidos. Esse esquema fornece uma visão bastante ampla de diversos aspectos do produto final publicado (ou seja, da obra traduzida), sobretudo dos aspectos extratextuais que o compõem; seus quatro estágios, que compreendem níveis macro e micro-estruturais, permitem a obtenção de uma visão panorâmica de tais aspectos.

Para atender ao objetivo deste estudo, será dada ênfase, primordialmente, ao primeiro e quarto estágios do esquema de Lambert e Van Gorp (1985); ao primeiro estágio, os ‘dados preliminares', por ele se ocupar dos aspectos extratextuais, que dão ao leitor uma idéia geral sobre o tipo de tradução que está lendo (os dados, que não fazem parte do texto de partida, mas de sua edição; tipos de editoras, anos de publicação, número de reimpressão, direitos autorais, capa, folha de rosto; informação metatextual no texto traduzido, isto é, introdução ou prefácio elaborado pelo tradutor e/ou pelo editor); e ao quarto estágio, o ‘contexto sistêmico', por abordar as oposições entre os níveis macro e microestruturais, e entre texto e teoria (normas, modelos, etc.); as relações intertextuais (outras traduções e o relacionamento entre esses textos e o texto traduzido em questão, e o texto de partida adotado); e as relações intersistêmicas (gênero textual, estilo), leitor e crítica. O segundo e o terceiro estágios são abordados apenas de forma breve, pois este estudo não prevê a análise mais aprofundada dos contos traduzidos nos níveis macro- e microestruturais.

Com relação à importância do estudo dos metatextos que suplementam os textos traduzidos, Susan Bassnett, salienta que,

uma área que se destacou muito, recentemente, é o estudo sistemático de depoimentos de tradutores sobre a tradução feitos por tradutores e linguistas em diferentes tempos e lugares. O estudo dos prefácios dos tradutores ensinanos muito, não apenas sobre os critérios adotados pelo tradutor individual, mas sobre o que esses critérios refletem da concepção de tradução partilhada pela comunidade em geral. (BASSNETT, 2003, p. xiii)

Bassnett (1998, p. 109-110) enfatiza ainda que é importante estudar não apenas as afirmações de tradutores na introdução de suas traduções, mas também aquelas veiculadas em revistas e jornais (artigos, crítica). Peter Newmark (1998, p. 35) também propõe o acréscimo de vários métodos de adição de informação suplementar à obra traduzida, dentre eles o prefácio do tradutor e o posfácio do tradutor. ${ }^{9}$

\footnotetext{
${ }^{8}$ Está assim organizado: dados preliminares; macroestrutura; microestrutura; e contexto sistêmico. O segundo estágio, o nível macroestrutural (macrolevel) compreende a comparação da estrutura específica do texto de partida com a do traduzido e envolve aspectos tais como: a divisão de capítulos, o número de parágrafos e de frases. O terceiro estágio, o nível microestrutural (microlevel) focaliza o texto enquanto linguagem, e aborda elementos tais como: seleção lexical, estruturas gramaticais dominantes, características estilísticas e formas de discurso (direto, indireto), narrativa, perspectiva, ponto de vista e níveis de linguagem (idioletos, dialetos). A comparação dos textos traduzidos com seus respectivos textos de partida neste estágio revela as estratégias adotadas pelo tradutor.

${ }^{9}$ Newmark (1998, p. 35) “adds two other 'methods' of supplementing information to his previous list: 5) In translator’s preface. 6) In translator’s afterword or postscript.”
} 
Para Gérard Genette $(1997)^{10}$, os paratextos ou as fontes extratextuais estão de alguma forma relacionados com o texto que acompanham e se configuram na forma de prefácios, introduções, posfácios, notas do tradutor, notas de rodapé, notas finais, títulos, subtítulos, dedicatórias, prólogos, advertências, notas prévias, nome de autor e de tradutor, capas, contracapas, notas editoriais, ilustrações, publicidade, bem como informações bibliográficas e legais. Esses textos externos à obra propriamente dita atuam como mediadores entre o texto e o leitor e podem influenciar a leitura e a recepção do texto.

Exame de quatro coletâneas de contos de Machado de Assis publicadas em inglês

A história da tradução da obra de Machado de Assis para o inglês começa nos Estados Unidos com as traduções de três contos. Treze anos após a morte do escritor brasileiro, o americano Isaac Goldberg organizou um volume de seis contos de escritores brasileiros, os traduziu para o inglês, e os publicou sob o título de Brazilian tales pela International Pocket Library, incluindo os três contos de Machado de Assis nesse seu "volume pioneiro” (Goldberg, 1921, p. 13).

Os contos de Machado de Assis traduzidos para o inglês que integram as quatro coletâneas objeto deste estudo são considerados pela crítica como pertencendo à fase mais madura do escritor (Gledson, 2008) e aparecem nas seguintes obras do autor brasileiro: Papéis avulsos (1882); Histórias sem data (1884); Várias histórias (1896); Páginas recolhidas (1899); Relíquias da casa velha (1906); e Outros contos (1859).

Para compor Brazilian tales foram selecionados três contos: The attendant's confession (O enfermeiro), The fortune-Teller (A cartomante) e Life (Viver); para a coletânea The psychiatrist and other stories (1963) foram escolhidos os seguintes doze contos apresentados com as respectivas datas de suas publicações: The psychiatrist (O alienista, 1881-1882), A woman's arms (Uns braços, 1885), The looking glass (O espelho, 1882), The secret heart (A causa secreta, 1885), The rod of justice (O caso da vara, 1891), The animal game (Jôgo do bicho, 1904), Midnight mass (Missa do galo, 1894), Father versus mother (Pai contra mãe, 1905), Education of a stuffed shirt (Teoria do medalhão, 1881), The holiday (Umas férias, 1905), Admiral's night (Noite de almirante, 1884) e Final request (Verba testamentária, 1882); para a coletânea The devil's church and other stories (1977) são escolhidos os seguintes dezenove contos: The bonzo's secret (O segredo do bonzo), Those cousins from Sapucaia (Primas de Sapucaia) ${ }^{11}$, Alexandrian tale (Conto alexandrino), The devil's church (A igreja do diabo), A strange thing (Singular ocorrência), Final chapter (Último capítulo), A second life (A segunda vida), Dona Paula (D. Paula), The diplomat (O diplomático), The companion (O enfermeiro), Evolution (Evolução), Adam and Eve (Adão e Eva), Eternal! (Eterno!), A celebrity (Um homem célebre), Mariana (Mariana), A canary's ideas (Idéias do canário), Pylades and Orestes (Pílades e Orestes), Funeral march (Marcha fúnebre), Wallow, swine! (Suje-se, gordo!); e para compor A chapter of hats: and other stories (2008) foram eleitos os seguintes vinte contos: In the Ark: three unpublished chapters of Genesis (Na Arca); The mirror: a sketch for a new theory of the human soul (O espelho); An alexandrian

\footnotetext{
${ }^{10}$ Ver também DERRIDA, 1982. O autor se refere aos elementos paratextuais como the outwork prefácios, rodapés, colchetes.

${ }^{11}$ Note-se que o conto "Primas de Sapucaia” é apresentado com título grafado errado, como “Rimas' de Sapucaia”! na página: <http://machado.mec.gov.br/index.php?view=article\&id=166 :conto>.
} 
tale (Conto alexandrino); A singular occurrence (Singular ocorrência); A chapter of hats (Capítulo dos chapéus); Those cousins from Sapucaia! (Primas de Sapucaia); Admiral's night (Noite de almirante, 1884); Evolution (Evolução); A schoolboy's story (Conto de escola); Dona Paula (D. Paula); The diplomat (O diplomático); The fortune-teller (A cartomante); The hidden cause (A causa secreta); A pair of arms (Uns braços); The cynosure of all eyes (A desejada das gentes); A famous man (Um homem célebre); The cane (O caso da vara); Midnight mass (Missa do galo); Pylades and Orestes (Pílades e Orestes); Father against mother (Pai contra mãe).

É interessante notar que nas três primeiras coletâneas de contos publicadas, o único conto repetido é "O enfermeiro". Parece ter havido um cuidado (excetuando-se os dois de Grossman, que já havia traduzido: Midnight mass [Missa do galo] e Admiral's night [Noite de almirante] que foram publicados pela Noonday e pela Harper's Bazaar, e que ele inclui em sua coletânea) para que não se repetissem os contos já traduzidos, priorizando contos nunca antes traduzidos, o que resultou na tradução de um maior número de contos diferentes. Entretanto, em 2008, com a publicação da quarta coletânea, organizada e traduzida por John Gledson, mais de trinta anos depois da publicação da terceira coletânea (1977), constata-se a retradução de vários contos (13) publicados anteriormente, quais sejam: O espelho; O caso da vara; Missa do galo; A causa secreta; Pai contra mãe; Conto alexandrino; Singular ocorrência; Primas de Sapucaia; Pílades e Orestes; Um homem célebre; O diplomático; Evolução; e A cartomante.

Em resumo, dos cerca de duzentos contos que Machado de Assis escreveu, apenas alguns (um pouco mais de vinte) circulam em língua inglesa nessas quatro coletâneas, pois, como se pode observar, são quase sempre os mesmos. Na coletânea de Gledson (2008) aparecem apenas quatro contos que não haviam sido contemplados nas três coletâneas anteriores: Na Arca, Capítulo dos chapéus, Conto de escola, e A desejada das gentes. Ressalte-se também que, exceto a primeira coletânea (1921), que reúne contos de diferentes autores (José de Medeiros e Albuquerque, Henrique Coelho Netto, e Carmem Dolores [cujo nome verdadeiro era Emilia Moncorvo Bandeira de Mello]), além de Machado de Assis e seus três contos, as outras coletâneas (1963, 1977, 2008) reúnem exclusivamente contos de Machado, o que pode revelar seu prestígio de um escritor que ao longo das décadas mereceu destaque individualizado.

Com relação aos dados mais gerais (dados preliminares) das coletâneas, pode-se destacar que as edições são bem cuidadas, com capa (primeiro capa dura e depois brochura) e tratamento gráfico de boa qualidade. No geral, a formulação e apresentação das obras são boas e de acordo com o esperado no sistema literário de chegada.

Os títulos dados às coletâneas, Brazilian tales (1921); The psychiatrist and other stories (1963); The devil's church and other stories (1977); e A chapter of hats and other stories (2008) remetem, primeiro, ao país de origem dos contos, o Brasil, na primeira coletânea, e ao nome de distintos contos nas outras três; na segunda a The psychiatrist (O alienista); na terceira a The devil's church (A igreja do diabo); e na quarta a A chapter of hats (Capítulo dos chapéus).

Os quatro volumes exibem basicamente as mesmas informações, com algumas particularidades. Na capa, todos apresentam o título da obra e o nome do escritor, o nome da editora sendo mencionado nas capas, exceto na quarta coletânea. O nome do escritor brasileiro aparece de forma completa apenas no volume de Goldberg (1921); na segunda, terceira e quarta coletâneas aparece de forma abreviada: 
Machado de Assis. Na capa da primeira coletânea o nome de Machado aparece junto com o dos outros autores brasileiros, mas figura em primeiro lugar; o nome do tradutor aparece na contracapa (primeira e quarta coletâneas) e na lombada (segunda e terceira coletâneas); na segunda e quarta coletâneas os nomes dos tradutores aparecem também na folha de rosto; na segunda, a lombada exibe o nome do escritor junto com os nomes dos dois tradutores.

Nas folhas de rosto constam uma combinação possível de nome do autor, título da coletânea, tradutor, editor, prefaciador, ilustrador, designer, número da edição, direitos autorais, ficha catalográfica e nome dos patrocinadores. A primeira coletânea (1921), pertencente à série The Texas Pan American series, foi patrocinada por uma companhia de enxofre, conforme o seguinte aviso: “The Texas Pan American Series is published with the assistance of a revolving publication fund established by the Pan American sulphur Company”. A segunda coletânea contou com o patrocínio da fundação Rockefeller: "Published with the assistance of a Grant from the Rockefeller Foundation”. Nessa segunda coletânea há menção do designer (designed by Theo Jung) e referência a três ilustrações, isto é, às gravuras retiradas do famoso arquivo de Otto Bettmann para os contos The devil's church, The diplomat e Eternal! ${ }^{12}$ Os direitos autorais da tradução são informados como pertencendo às editoras em três das coletâneas: The four seas company (1921), The Regents of University of California Press (1963) e University of Texas Press (1977); a exceção é a quarta coletânea (2008), cujos direitos autorais pertencem ao tradutor, John Gledson, e não à editora Bloomsbury. quatro obras:

Na página seguinte à folha de rosto, o nome do tradutor é mencionado nas

\begin{tabular}{|l|l|}
\hline 1921 & "translated from the Portuguese with an introduction by Isaac Goldberg" \\
\hline 1963 & "translated by William L. Grossman and Helen Caldwell" \\
\hline 1977 & "translated by Jack Schmitt and Lorie Ishimatsu” \\
\hline 2008 & "translated from the Portuguese with an introduction by John Gledson" \\
\hline
\end{tabular}

Além disso, há a indicação de que a tradução tem como texto de partida uma obra do português (primeira e quarta coletâneas), sinalizando ao leitor que está lendo um texto traduzido. E apenas na primeira coletânea são citadas outras obras publicadas pela editora, que incluem nomes conhecidos como Guy de Maupassant, Edgar Allan Poe, Thomas Hardy e Oscar Wilde.

Na contracapa da primeira coletânea (1921) consta que a obra é dedicada a um professor de francês e espanhol da Univeridade de Harvard: “J.D.M. Ford, Smith Professor of the French and Spanish languages, Harvard University”. Consta também que Goldberg é autor de obra sobre literatura brasileira: "Goldberg also wrote Brazilian Literature with a Foreword by J.D.M. Ford, which was published in New York by A. A. Knopf, in 1922. xiv-303p.”, e que é o autor de Studies in SpanishAmerican literature (1920).

O sumário apresenta a ordem sistemática da estrutura das coletâneas e está presente em todas as quatro. Na coletânea de 1921 os títulos dos três contos encontram-se em inglês e o nome do escritor aparece logo abaixo deles (não há

\footnotetext{
12 É interessante ressaltar que aparecem ilustrações, gravuras em todos os demais contos desta coletânea, mas não há nenhum comentário sobre elas.
} 
nenhuma referência aos títulos em português na obra); na de 1963 os títulos dos doze contos estão em inglês e abaixo deles tem-se os títulos correspondentes em português, o ano de publicação no Brasil e os nomes dos tradutores (que vêm escrito ao lado de cada um dos doze contos que compõem essa coletânea; William Grossman traduziu quatro contos e Helen Caldwell oito); já a coletânea de 1977 apresenta apenas os títulos dos dezenove contos em inglês; e a coletânea de 2008 também apresenta apenas os títulos dos vinte contos em inglês.

Nos sumários, as primeira, terceira e quarta coletâneas contêm uma "Introdução" elaborada pelo tradutor (ou por um deles, como é o caso da segunda coletânea, em que apenas um deles, Grossman, escreve a introdução); na terceira e quarta coletâneas há ainda no Sumário a referência a uma "Nota do tradutor”. Na terceira coletânea, na "Nota dos tradutores", localizada somente ao final da obra, são apresentados os títulos e as datas de publicação dos contos em português, bem como a referência/edição adotada: “(volume 2 da edição Aguilar de 1962)”. Os dois tradutores também identificam os contos que cada um traduziu. Jack Schmitt e Lorie Ishimatsu salientam que ambos leram os textos um do outro, mas que cada um ficou responsável primordialmente pelos títulos indicados na coletânea. Já na quarta coletânea, o tradutor John Gledson acrescenta notas explicativas ao final da obra para catorze dos vinte contos traduzidos, com o fim de esclarecer aspectos culturais, históricos e geográficos, dentre outros, que ele também comenta na sua "Introdução de tradutor. A única das quatro coletâneas que apresenta uma nota sobre o tradutor, ao final da obra, em página interna, é a quarta: “a note on the translator - John Gledson”.

No que concerne à tradução dos títulos dos contos, são quase sempre traduzidos de forma bastante literal: An alexandrian tale (Conto alexandrino); $A$ singular occurrence (Singular ocorrência); A chapter of hats (Capítulo dos chapéus); Those cousins from Sapucaia! (Primas de Sapucaia); Admiral's night (Noite de almirante); Evolution (Evolução); A schoolboy's story (Conto de escola); The diplomat (O diplomático); The fortune-teller (A cartomante); The hidden cause (A causa secreta); A pair of arms (Uns braços); A famous man (Um homen célebre); Midnight mass (Missa do galo); Pylades and Orestes (Pílades e Orestes); Father against mother (Pai contra mãe).

Vale observar os títulos dos contos que contam com retraduções cujos títulos são expandidos se comparados com os títulos no texto de partida. É o caso dos seguintes contos: “A arca” é traduzido como In the Ark: three unpublished chapters of Genesis (Gledson, 2008); "O espelho" é traduzido como The mirror: a sketch for a new theory of the human soul (Gledson, 2008); "O enfermeiro" é traduzido como The attendant's confession (Goldberg, 1921); "O caso da vara” é traduzido como The rod of justice (Caldwell, 1963); há um caso de tradução do título em que ocorre a expansão da abreviatura que corresponde ao pronome de tratamento "dona" na tradução do conto “D. Paula”, Dona Paula (Schmitt, 1977) / Dona Paula (Gledson, 2008).

A tradução do conto “A desejada das gentes” como The cynosure of all eyes (Gledson, 2008) propõe um título com mais impacto, ou que seja mais apropriado tematicamente, do que o original. De maneira análoga, opina Clifford Landers (2001, p. 150) quando se refere à tradução de Grossman para o título "Memórias Póstumas 
de Brás Cubas"13: Epitaph of a small winner, publicada nos Estados Unidos pela Noonday (1952). ${ }^{14}$

Com relação aos tradutores, os seis que selecionaram e traduziram os contos que compõe as quatro coletâneas são ligados à academia; além disso, são, em geral, professores de literatura brasileira, que, com algumas exceções, também atuam em outras áreas do saber.

Isaac Goldberg (1887-1938) foi jornalista, crítico, tradutor, professor de literatura brasileira na University of Harvard, e é, aparentemente, o primeiro tradutor a apresentar obras de Machado de Assis em tradução para o inglês.

Helen Caldwell (1904-1987) ${ }^{15}$, professora de latim e grego no Department of Classics da University of California, Los Angeles (UCLA), tradutora e crítica norteamericana, traduziu, além dos contos já citados, os seguintes romances de Machado de Assis: Dom Casmurro (1953), Esaú e Jacó (1965), Memorial de Aires (1972) e Helena (1984). Escreveu dois livros sobre a obra de Machado: The Brazilian Othello of Machado de Assis: a study of Dom Casmurro (1960) e The Brazilian master and his novels (1970). Recebeu a Ordem Nacional do Cruzeiro do Sul do governo brasileiro em 1959 e o prêmio Machado de Assis da Academia Brasileira de Letras em 1963.

Wiliam Leonard Grossman (1906-1980) ${ }^{16}$, professor da área de economia e transportes da University of New York, esteve no Brasil entre 1948-1952 para trabalhar no Instituto de Aeronáutica - ITA. Grossman foi o primeiro tradutor para o inglês dos romances de Machado de Assis (cf. nota 14). Grossman também organizou a antologia Modern Brazilian short stories, publicada pela California University Press, em Berkeley, em 1967, com obras de dezesseis escritores brasileiros, dentre eles Guimarães Rosa, Graciliano Ramos, Marques Rebelo, Mário de Andrade e Rachel de Queiroz.

Helen Caldwell e William L. Grossman são consagrados pela crítica internacional por terem traduzido obras de Machado de Assis e de vários outros escritores brasileiros. Jack Schmitt também publicou artigos sobre contos brasileiros e traduziu obras de Raul Zurita e Pablo Neruda. Lorie Chieko Ishimatsu escreveu sua dissertação e publicou uma obra sobre a poesia de Machado de Assis, Poetry of Machado, publicado pela Albatros Hispanofilia, em 1984.

\footnotetext{
${ }^{13}$ Interessante notar que Grossman é o primeiro tradutor para o inglês dos romances de Machado de Assis. Em 1951, Grossman traduziu para o inglês, e publicou por conta própria, "Memórias póstumas de Brás Cubas” pela São Paulo Editores. O título dessa edição é Posthumous memoirs of Brás Cubas. De acordo com entrevista concedida a Otto Schneider, somente em 1952 é que Grossman publicou por intermédio de um amigo poeta, Cecil Hemley, esse romance nos Estados Unidos, com o título Epitaph of a small winner pela editora Noonday.

${ }^{14}$ Em 1997 a editora Bloomsbury, publicou o romance com o mesmo título na Inglaterra, em Berlin e em New York.

${ }^{15}<$ http://texts.cdlib.org/view?docId=hb6z09p0jh\&chunk.id=div00008>

${ }^{16}$ O Prêmio "William L. Grossman” de Excelência em Economia dos Transportes, do Núcleo de Economia dos Transportes - NECTAR do Instituto Tecnológico de Aeronáutica (ITA), de São José dos Campos é concedido ao melhor artigo científico apresentado no âmbito do Simpósio de Economia dos Transportes (SET) e é composto por certificado e convite para publicação de artigo, com menção de destaque, no JTL|RELIT - Journal of Transport Literature. William Grossman é o patrono do Laboratório de Transportes do ITA (LABTAR), tendo sido pioneiro em pesquisas e ensino na área de Economia dos Transportes no Brasil. <http://www.transport-planning.org/2012/05/premio-william-lgrossman-7-set.html> Acesso em 28 set. 2012.
} 
John Gledson (1945-), como a nota sobre o tradutor acrescentada à quarta coletânea indica, foi professor de literatura brasileira na University of Liverpool, Inglaterra, e publicou livros e ensaios sobre a obra de Machado de Assis e Carlos Drummond de Andrade. Traduziu Dom Casmurro (1998) além de obras de Milton Hatoum e Roberto Schwarz.

Com relação às editoras que publicaram as obras de Machado em inglês, a maioria delas pertence a empresas particulares ou está ligada a universidades. Dado o baixo número de exemplares publicados por essas editoras ${ }^{17}$ em cada tiragem, é de se supor que não visaram lucro com essas traduções. Elas revelam sobretudo o interesse na política e na difusão cultural da literatura brasileira no cenário anglo-americano. Pode-se dizer que fato semelhante ocorre no caso das quatro coletâneas em estudo, que focalizam, crê-se, um público mais restrito, geralmente apenas o acadêmico.

As editoras que publicaram as quatro coletâneas (reimpressões, edições), incluem: Brazilian tales: The four seas Co. (1921), International pocket library (1921, 1965), George Allen \& Unwin (1924); The pshychiatrist and other stories: University Press of California, Berkeley e Los Angeles (1963), e Peter Owen, Londres (1966); The devil's church and other stories ${ }^{18}$ : University of Texas Press, de forma simultânea em Austin e Londres; A chapter of hats: and other stories: Bloomsbury, em Londres, Berlin e New York (2008).

Uma pesquisa na internet, em páginas de editoras e de bibliotecas universitárias do mundo anglófono, indica que Machado de Assis tem muitas de suas obras disponíveis para consulta e compra. Em março de 2013, a conhecida livraria online Amazon, por exemplo, informava que as quatro coletâneas podiam facilmente ser adquiridas. Além disso, Brazilian tales (1921) já está em domínio público ${ }^{19}$ e pode ser encontrada na página do Projeto Gutenberg na internet. The devil's church and

\footnotetext{
${ }^{17}$ Com relação aos romances de Machado de Assis, a editora Peter Owen, da Inglaterra, por exemplo, publicou em torno de 1.500 a 2.000 exemplares, conforme informação em e-mail para a autora enviado em 28 de junho de 2001.

McCABE , Daniel. Sales figures Machado de Assis (mensagem pessoal). Mensagem recebida por $<$ V.Hatje-Faggion@warwick.ac.uk> em 28 de jun. de 2001. “[...] but it is safe to assume that most Peter Owen print turns for this sort of (lesser-known) literature knock around in the vicinity of 1500 copies, very occasionally running to 2000.”

${ }^{18}$ De acordo com BRAZILIAN AUTHORS TRANSLATED ABROAD, 1994, The devil's church and other stories foi publicado pela Carcanet, Manchaster em 1985 e pela Grafton Books, Londres em 1987 (p.113).

Conforme já mencionado, além dessas editoras, alguns contos já foram publicados anteriormente: Grossman, Midnight mass (Missa do Galo) e Admiral's night (Noite de Almirante), que foram publicados pela Noonday e pela Harper's Bazaar, respectivamente.

Wilson Loria traduziu o conto Espelho/The mirror em 1995 e o disponibiliza na internet. Loria é escritor e editor de Samba (a newsletter dedicated to Brazilian arts in the US/ Informativo dedicado às Artes brasileiras nos Estados Unidos). <http://www.brazzil.com/pages/shjul95a .htm> Acesso em 30 junho 2013.

The alienist (O alienista) foi traduzido por Alfred Mac Adam com ilustração de Carroll Dunham e foi publicado pela editora The Arion Press, San Francisco, Califórnia, 1998. De acordo com a página da editora, <http://www.arionpress.com/catalog/055.htm> a edição de 250 cópias (cada cópia ao custo de $\$ 450$ dólares devido às ilustrações acrescentadas à obra ) está esgotada. (Edition of 250, \$450.00. Out of print.)

19 <http://www.gutenberg.org/2/1/0/4/21040/>; < <http://www.dominiopublico.gov.br/pesquisa/D etalheObraForm.do?select_action=\&co_obra=86813>; $\quad<$ http://books.google.com.br/books?id=t _BpiafiUsIC>
} 
other stories, por sua vez, é impressa e adquirida sob encomenda - This is a print-ondemand title -, conforme consta na página da editora da university of Texas Press. ${ }^{20}$

O número de edições, re-edições e re-traduções parece revelar um contínuo interesse na obra de Machado de Assis. Em outras palavras, alguém está lendo, comprando e, com isso, tal aceitação promove um destino promissor para a difusão da obra de Machado no mundo de língua inglesa. O fato é que, muito provavelmente, esse público seja quase todo da esfera acadêmica, e frequenta cursos de língua portuguesa e literatura brasileira.

As editoras tem um papel fundamental nessa disseminação da obra do escritor brasileiro, pois dão espaço para que apareça, fique visível para os leitores de língua inglesa e se mantenha viva ao longo das décadas. Elas utilizam diversas estratégias que podem ajudar a incrementar as vendas. As várias edições e reimpressões demonstram que se trata de um gênero (literatura estrangeira traduzida) com vitalidade, embora com aparente menor viabilidade comercial (muitas vezes ainda tido como gênero literário periférico).

Conforme mencionado anteriormente, no sumário das quatro coletâneas há a referência aos metatextos. Além do conto traduzido, propriamente dito, outros textos integram essas coletâneas. Esses metatextos incluem a introdução do tradutor e o texto da capa e contracapa, que são elaborados para atender objetivos referentes a estratégias diversas como, por exemplo, a estratégia da familiaridade do novo leitor com o gênero literário específico, com o autor estrangeiro e sua obra, e as estratégias de marketing e de fins comerciais.

É interessante ressaltar que os organizadores das coletâneas, que são também os tradutores dos contos, não se referem em nenhum momento à questão da tradução propriamente dita em seus ensaios. Não abordam dificuldades, escolhas, tomadas de decisões, enfim, não comentam o processo tradutório. A única coletânea que apresenta um breve comentário sobre a qualidade da tradução é a quarta, de John Gledson.

De modo geral, nas introduções às traduções dos contos, os tradutores apontam razões para suas seleções e traduções, comparam Machado a escritores famosos do mundo anglo-americano e europeu, e discutem as estruturas e temáticas dos contos.

Goldberg, o organizador de Brazilian tales, por exemplo, elabora uma introdução com vinte e três páginas intitulada Some informal preliminary remarks e a subdivide em quatro partes. Na primeira, aborda brevemente aspectos da literatura brasileira e sua formação; na segunda, faz um histórico da literatura brasileira e a divide em quatro fases, enfatiza a dependência do sistema literário brasileiro em relação aoutros sistemas literários (a saber, os de França e Portugal), e comenta sobre autores brasileiros importantes, como José de Alencar, Visconde de Taunay, Aluísio de Azevedo e Graça Aranha. Goldberg faz ainda um exercício de comparação interliterária, citando o colombiano, Jorge Isaac (autor de María) e o brasileiro Visconde de Taunay (autor de "Inocência”). Na terceira parte, Goldberg apresenta três dos quatro autores selecionados para integrar sua coletânea de contos; e, ao fim, aborda a literatura escrita por mulheres; os exemplos dados referem-se às obras de escritoras de Cuba, México, Peru e Brasil, sendo que Carmen Dolores (1852-1910) é a escritora brasileira incluída na coletânea, com o conto Aunt Zezés tears.

\footnotetext{
${ }^{20}<$ http://utpress.utexas.edu/index.php/books/macdev\#sthash.5GdMHzJE.dpuf>.
} 
Para justificar a apresentação de obras brasileiras que merecem maior reconhecimento pelo leitor de língua inglesa, Goldberg (1921, p. 13) enfatiza, no início dos pujantes anos 20, a crescente importância do Brasil na esfera comercial e o interesse no estudo do português ${ }^{21}$. Goldberg (p.26) ${ }^{22}$ também destaca que Machado de Assis foi eleito unanimemente presidente da Academia Brasileira de Letras, função que ocupou desde sua fundação (1897) até a morte do grande autor brasileiro (1908). Além disso, salienta que a coletânea é uma amostra modesta e, por isso, não tem pretensão de ser completa, finalizada e infalível (p.26) ${ }^{23}$.

Jack Schmitt e Lorie Chieko Ishimatsu (1977, p. ix) ${ }^{24}$, por sua vez, destacam que sua seleção dos contos tem por objetivo apresentar uma amostra do estilo particular de Machado: "acreditamos que todos os nossos contos, considerados de forma global, representam o estilo particular e a visão de mundo de Machado.” De forma semelhante, Grossman (1963, p.x ${ }^{25}$ menciona que, no conjunto, os contos selecionados propiciam uma boa amostra dos conceitos e métodos de Machado Aunt Zeze's tears, embora obviamente não totalmente representativa. Goldberg (1921, p. $24)^{26}$ alude ao crítico brasileiro José Veríssimo para salientar que os três contos fazem parte de Várias histórias - "the three tales by Machado de Assis in Goldberg's volume are translated from his Varias histórias" - e para explicar a ironia presente nesses contos, que também é característica de seus melhores romances - "that same bittersweet philosophy and gracious, if penetrating, irony which inform these tales are characteristic of his larger romances.”

$\mathrm{Na}$ introdução a sua tradução, John Gledson (2008, p. 1$)^{27}$ salienta que Machado de Assis já tem oito de seus nove romances traduzidos para o inglês, mas que o escritor merece ser conhecido também pelos contos, do qual é um dos grandes pioneiros, na forma que conhecemos o gênero na literatura mundial. Gledson (p. 1) ${ }^{28}$ ainda destaca que já foram publicadas duas coletâneas de contos em inglês, em 1963 e 1977, e que uma nova antologia com novas traduções há muito tempo já era necessária, justificando assim a publicação da coletânea de sua autoria.

\footnotetext{
${ }^{21}$ [...] The growing importance of Brazil as a commercial nation, together with a corresponding increase of interest in the study of Portuguese (a language easily acquired by all who know Spanish) will have the desirable effect of making known to the English reading public a selection of works deserving of greater recognition.

O leitor de língua inglesa também é alertado de sua oportunidade de entrar em contato com a obra do escritor brasileiro quando Goldberg se refere a sua coletânea como "this little pioneer volume” (p. 13).

${ }^{22}$ When the Brazilian Academy of Letters was founded in 1897, Machado de Assis was unanimously elected president and held the position until his death.

${ }^{23}$ The present selection of tales makes no pretense at completeness, finality or infallibility of choice. This little book is, so to speak, merely a modest sample-case.

${ }^{24}$ We believe that all our stories, taken collectively, are representative of Machado's unique style and world view.

${ }^{25}[\ldots]$ taken together, these and the nine other stories provide a fair, although of course not wholly representative, sample of Machado's concepts and methods.

26 "the three tales by Machado de Assis in Goldberg's volume are translated from his Várias histórias", "that same bitter-sweet philosophy and gracious, if penetrating, irony which inform these tales are characteristic of his larger novels."

27 "Eight of his nine novels have been translated into English [...] he deserves to be known for his stories too- in fact, he is one of the great pioneers of the genre as we know it today.”

28 "Two collections have been published in English, in 1963 and 1977- a new anthology, with new translations, is long overdue."
} 
É interessante notar que Goldberg se dirige ao leitor anglo-americano no sentido de alertá-lo das diversas dificuldades de produção dos autores selecionados para integrar a sua coletânea, mas que apesar disso, esses autores tem obras de excelente qualidade e não precisam parecer exóticas ao leitor de língua inglesa. Esse alerta parece ter a importante função de ressaltar a alta qualidade da obra de Machado já desde os anos 1920, apesar das circunstâncias desfavoráveis que cercaram sua produção:

Ao considerar a obra desses autores representados neste pequeno volume pioneiro, dever-se-ia levar constantemente em conta as muitas dificuldades que os autores enfrentam nos países da América de língua espanhola e portuguesa: um público leitor pequeno, a falta de editoras, o alto índice de analfabetismo e a instabilidade política. Em tais circunstâncias não é de se espantar que uma obra com esta excelente qualidade tenha sido elaborada, mas sim é de se admirar com o fato de que ela tenha sido efetivamente produzida. (GOLDBERG, 1921, p. 13) ${ }^{29}$

Os tradutores/organizadores das quatro coletâneas em estudo comparam Machado de Assis com autores conhecidos do público anglo-americano. Goldberg, por exemplo, compara Machado de Assis com autores famosos, já estabelecidos no sistema literário de chegada, salientando que a obra do escritor brasileiro se assemelha às de Poe, Hawthorne e Maupassant:

é interessante destacar a popularidade de Poe e Hawthorne na America do Sul. [...] A introspecção desses escritores, como a de Maupassant e autores similares, aponta para uma característica similar a dos brasileiros. Esta busca interior [...] a preocupação com problemas psicológicos [...] Estórias como O enfermeiro/ The attendants's confession são elaboradas com refinamento de pensamento e linguagem. Elas não são, como muito da literatura brasileira tem de parecer ao leitor estrangeiro, exóticas. Elas pertencem às obras do mundo por causa do apelo humano do conteúdo e do tratamento elaborado dado a elas. (GOLDBERG, 1921, p. 23) ${ }^{30}$

William L. Grossman elaborou a introdução do volume de contos que ele e Helen Caldwell organizaram. Em quase quatro páginas, o tradutor apresenta Machado de Assis como "a shy mulatto" e menciona que até 1952, com a publicação de Epitaph of a small winner, o escritor brasileiro era praticamente desconhecido nos

\footnotetext{
${ }^{29}$ In considering the work of [....] the authors represented in this little pioneer volume one should bear continually in mind the many handicaps under which authorship labors in Portuguese and Spanish America: a small reading public, lack of publishers, widespread prevalence of illiteracy, instability of politics. Under the circumstances it is not so much to be wondered at that the best work is of such a high average as that it was done at all.

${ }^{30}$ In connection with the special character of the tales included in the present sample of modern Brazilian short stories, - particularly those by Machado de Assis and Medeiros de Albuquerque- it is interesting to keep in mind the popularity of Poe and Hawthorne in south America. The introspection of these man, as of de Maupassant and kindred spirits, appeals to a like characteristic of the Brazilians. Such inner seeking [...] preoccupation with the psychological problems ... Stories like The Attendants's Confession are written with a refinement of thought as well of language. They are not, as so much of Brazilian literature must perforce seem to the stranger's mind, exotic. They belong to the letters of the world by virtue of the human appeal of the subject and the mastery of their treatment.
} 
Estados Unidos. Grossman (1963, p. vii ) ${ }^{31}$ cita Dudley Fitts para destacar que Machado de Assis é reconhecido nos Estados Unidos como "uma força literária que transcende questões de nacionalidade e linguagem, certamente comparável a Flaubert, Hardy ou James” [...]. Jack Schmitt e Lorie Chieko Ishimatsu (1977) também comparam o escritor brasileiro com Herman Melville (p. ix) e Henry James (p. xii). Grossman (1963, p. vii) salienta que os temas originais e a perfeição da forma fazem de Machado de Assis um "mestre mundial do conto" (make him a world master of the short story). Conforme já mencionado, em sua introdução, Grossman (1963) informa que já havia traduzido dois contos (Midnight mass ["Missa do galo"] e Admiral's night ["Noite de almirante"], publicados pela Noonday e pela Harper's Bazaar, e que ele incluiu nessa sua coletânea. Esses dois contos passam, pois, a ser republicados e constituem mais uma oportunidade de veiculação da obra do escritor brasileiro.

A introdução de Jack Schmitt e Lorie Chieko Ishimatsu (1977) é bem mais breve que a de Goldberg e tem quase o mesmo tamanho da introdução de Grossman (1963) e Gledson (2008). Em aproximadamente cinco páginas, Schmitt e Ishimatsu $(1977)^{32}$ enfatizam que "o conto brasileiro moderno começa com as obras da fase madura de Joaquim Maria Machado de Assis” (1977, p. ix) e que "nenhum outro escritor no Brasil se destacou mais na técnica da elaboração do conto antes de 1930 do que Machado de Assis” (1977, p. ix). Eles ressaltam ainda que, com relação à técnica de elaboração do conto, "Machado estava décadas à frente de seus contemporâneos e pode, por isso, ser considerado mais moderno do que muitos dos próprios modernistas. Ele também é referência obrigatória para quem estiver interessado no desenvolvimento da literatura brasileira moderna” (1977, p. xii). Para Schmitt e Ishimatsu (1977, p. ix), a obscuridade da obra de Machado nos Estados Unidos está relacionada ao fato de o português não ser amplamente difundido no país, e as traduções de seus romances e contos, no inglês, somente foram publicadas recentemente. Eles fazem agradecimento especial às traduções que consideram excelentes de Helen Caldwell e de William L. Grossman.

Goldberg (1921, p. 23) ${ }^{33}$ elogia Machado destacando sua importância na literatura brasileira e enfatizando que ele é o maior escritor dentre os quatro autores escolhidos para sua coletânea. Jack Schmitt e Lorie Chieko Ishimatsu (1977, p. ix) ${ }^{34}$ também destacam que Machado de Assis "é aclamado quase que de forma unânime o maior escritor brasileiro.”

Os metatextos que integram as quatro coletâneas de contos também podem ter sido elaborados para atender objetivos referentes a estratégias de marketing e comerciais, conforme indica o texto nas contracapas. Na contracapa do volume organizado por Goldberg (1921), por exemplo, consta que Machado foi traduzido para o inglês porque ele escreveu um dos melhores contos da literatura brasileira e é um

\footnotetext{
${ }^{31}$ a literary force transcending nationality and language, comparable certainly to Flaubert, Hardy, or James. p. vii.

32 [...] The modern Brazilian short story begins with the mature works of Joaquim Maria Machado de Assis p. ix [...] no other writer in Brazil achieved his technical mastery of the story form before the 1930s. p. ix [...] In his technical mastery of the short story, Machado was decades ahead of his contemporaries and can still be considered more modern than most of the modernists themselves. He is also an obligatory point of reference for anybody interested in the development of modern Brazilian literature. p.xii.

${ }^{33}$ chief among the writers here represented stands Joaquim Maria Machado de Assis (1839-1908).

${ }^{34}$ is acclaimed almost unanimously as Brazil's greatest writer.
} 
dos maiores autores do Brasil, a grande nação do hemisfério sul. ${ }^{35}$ A contracapa da coletânea de Gledson (2008) apresenta as opiniões de escritores famosos como Salman Rushdie, que destaca o tipo de humor empregado por Machado de Assis: "the kind of humour that makes skulls smile”; ou como Louis de Berniéres, escritor bestseller que afirma que o escritor mereceu um funeral com honras de estado: "He was on of the few writers who not only received a state funeral, but actually deserved it". Notas publicadas em jornais de prestígio como Daily Telegraph, New York Times Book Review e Irish Times também revelam Machado como um escritor que escreveu para além de seu tempo e com qualidade original de alcance universal. Eileen Battersby (Irish Times, contracapa, Gledson, 2008) afirma que "Machado de Assis foi uma força literária que ultrapassou os limites de nacionalidade e língua e, certamente, é comparável a Flaubert, Hardy ou James.”36

A nota da editora Bloomsbury (contracapa, Gledson, 2008) também $^{37}$ salienta que a obra de Machado de Assis é admirada por escritores tais como Salman Rushdie, Carlos Fuentes, Woody Alllen e Susan Sontag. Além disso, a nota ainda destaca que os contos são da fase madura da obra do escritor, que tem ecos em Poe e Gogol, antecipam Joyce e têm sido comparados a Chekhov, Maupassant e Henry James. Eileen Battersby (Irish Times- contracapa, Gledson, 2008) também alude ao efeito surrealista de Machado de Assis presente na obra do escritor Paul Auster: "sempre de novo através dessas parcelas pontuais, elegantes e brilhantes de loucura

${ }^{35}$ Dr Isaac Goldberg, noted authority on Latin-American literature... selected for this volume half a dozen of the best-known short stories in Brazilian literature [...] this volume gives an opportunity to know some of the outstanding authors of the great nation in the Southern Hemisphere.

36 "Machado de Assis was a literary force, transcending nationality and language, comparable certainly to Flaubert, Hardy, or James.”

${ }^{37}$ Machado de Assis (1839-1908) is the great Brazilian author of Philosopher or Dog? and Epitaph of a small winner, whose work is admired by writers as various as Salman Rushdie, Carlos Fuentes, Woody Alllen and Susan Sontag. Taken from his mature period, these dazzling stories echo Poe and Gogol, antecipate Joyce, and have been compared to the writing of Chekhov, Maupassant and Henry James [...].”

Note-se que a editora Bloomsbury publicou as duas obras traduzidas com esses títulos, diferente de outras traduções publicadas por outras editoras.

Memórias póstumas de Brás Cubas:

Machado de Assis. Epitaph of a small winner. Tradução de William Grossman. New York: The Noonday Press, 1952.

Posthumous reminiscences of Braz Cubas. Tradução de E. Percy Ellis. Rio de Janeiro: Instituto Nacional do Livro, 1955.

—. The posthumous memoirs of Brás Cubas. Tradução de Gregory Rabassa. New York and Oxford: Oxford University Press, 1997.

. Epitaph of a small winner. Tradução de William Grossman. New York: Farrar, Straus and

Quincas Borba: Giroux, 2008.

Machado de Assis. The heritage of Quincas Borba. Tradução de Clotilde Wilson. New York and London: W.H.Allen, 1954. Philosopher or dog? Trad. De Clotilde Wilson. New York: Farrar, Straus and Giroux, 1992. . Philosopher or dog? Trad. de Clotilde Wilson. Bloomsbury: London, New York, Berlin, 1997. Quincas Borba. Tradução de Gregory Rabassa. New York and Oxford: Oxford University Press, 1998. 
controlada, de Assis... consegue atingir o efeito surrealista que Paul Auster tem tentado obter ao longo de toda a sua carreira.”38

Elementos como modernidade, atualidade e originalidade também são ressaltados nos metatextos: "[...] sua sensibilidade moderna e humor evidente permanecem completamente únicos” (nota da editora Bloomsbury- contracapa, Gledson, 2008). ${ }^{39}$

A nota do jornal Daily Telegraph (contracapa, Gledson, 2008) ${ }^{40}$ enfatiza que embora seja evocada a atmosfera carioca do final do século XX muitas das estórias poderiam muito bem ter sido escritas na época atual.

Já em 1921, ao longo da introdução de sua coletânea, Goldberg (1921, p. 24) deixa explícita, enfatiza e repete a questão da importância e do prestígio de Machado de Assis na literatura brasileira. Ele ressalta que Machado de Assis está no mesmo nível dos escritores americanos. Essas razões podem ser apontadas como motivos para a seleção de obras brasileiras serem traduzidas para o inglês. Goldberg assim alude ao crítico brasileiro José Veríssimo para apresentar e elogiar o escritor brasileiro em seu sistema literário de origem:

[...] por causa da importância de Machado de Assis para a literatura brasileira [...] Machado de Assis publicou seu décimo quinto volume e sua quinta coletânea de contos ... Para dizer que em nossa literatura Machado de Assis é um caso à parte, que ele é com razão o melhor dos escritores brasileiros de ficção; que ele tem um rara capacidade de assimilação e evolução que fazem dele um escritor da segunda geração de românticos sempre um contemporâneo, um moderno sem ter sacrificado nada com relação a estética literária vigente ou copiado alguma nova; acima de tudo conservando sua própria e distinta personalidade ... isto apenas para repetir o que já tem sido dito muitas vezes. (GOLDBERG, 1921, p. 24-25) ${ }^{41}$

Ainda aludindo a Veríssimo, Goldberg (1921, p. 26) apresenta Machado como "gênio da literatura brasileira" e o único escritor universal do país: "a maior distinção do gênio Machado de Assis na literatura brasileira está relacionada ao fato de que ele é o único escritor verdadeiramente universal que nós possuímos sem precisar que ele deixe de ser bem brasileiro."42

Com o propósito semelhante de destacar a relevância do escritor brasileiro no sistema literário brasileiro, bem como seu talento literário, Goldberg também alude a Oliveira Lima, que foi professor na Harvard University entre 1915-1916:

\footnotetext{
38 "Time and again throughout these sharp, elegant and always brilliantly understated slices of controlled madness, de Assis... achieves the elusive offbeat surrealist effect that Paul Auster has been pursuing for his entire career."

39 “[...] yet his modern sensibility and clear-eyed humour remain utterly unique.”

40 "The atmosphere of Rio de Janeiro in the late 1800s is evoked... Yet many of these stories could have been written about our own times."

${ }^{41}$ [...] Both because of the importance of Machado de Assis to Brazilian literature ... Machado de Assis published his fifteenth volume and his fifth collection tales .... To say that in our literature Machado de Assis is a figure apart, that he stands with good reason first among our writers of fiction, that he possesses a rare faculty of assimilation and evolution which makes him a writer of the second Romantic generation, always a contemporary, a modern, without on this account having sacrificed anything to the latest literary fashion or copied some brand-new aesthetic, above all conserving his own distinct, singular personality ... is but to repeat what has been said many times already.

42 “[... ] the highest distinction of the genius of Machado de Assis in Brazilian literature is that he is the only truly universal writer we possess, without ceasing on that account to be really Brazilian.”
} 
[Machado de Assis] foi bem sucedido por causa de seu talento extraordinário como escritor, de sua profunda dignidade literária, de unidade de uma vida que foi inteiramente dedicada ao cultivo da beleza intelectual, e pelo prestígio recebido pela sua obra e personalidade; apesar de sua natureza avessa aos holofotes e pouco inclinada à aparição pública, Machado de Assis foi considerado e respeitado como o primeiro entre os escritores de seu país. (GOLDBERG, 1921, p. 27) ${ }^{43}$

Os tradutores americanos e ingleses muito já tem contribuído para a circulação das obras de Machado de Assis em inglês, e se inscrevem explicitamente na obra traduzida e publicada nas quatro coletâneas. Segundo Sherry Simon (1990, p. 111), a presença de prefácios e a sua frequência em diferentes períodos históricos (por exemplo, na Idade Média e no Renascimento) é uma indicação da ênfase que tem sido dada ao tradutor, já que o prefácio anuncia a presença de uma outra manifestação discursiva, "the presence of a second hand", e a inscrição de duas assinaturas, uma "double signature", dando, assim, mais visibilidade e reconhecimento ao trabalho do tradutor.

Pelos dados apresentados nos metatextos, pode-se salientar que desde 1921, a fama e o prestígio de Machado de Assis, e seu reconhecimento, têm se perpetuado e reafirmado no mundo de língua inglesa.

As sucessivas coletâneas publicadas por diferentes editoras no mundo angloamericano afirmam esse interesse renovado de leitores de língua inglesa pela obra de Machado (leitores de tradução de contos e romances). Nessa travessia, nesse movimento de migração de um sistema literário para outro, do hemisfério sul para o norte, a obra compilada traduzida e publicada circula com marcas editoriais (opiniões de autores famosos no sistema literário de chegada, na capa e na contracapa) e marcas discursivas (inclusão de metatextos) que revelam a expectativa suposta do novo leitor.

Durante o século XX, os tradutores de Machado compararam esse escritor brasileiro com autores conhecidos do público mais amplo. Três das coletâneas em estudo foram publicadas num século (1921, 1963, 1977), e uma quarta coletânea $(2008)^{44}$ já inaugurou o novo século, XXI, renovando o interesse demonstrado pela obra de Machado de Assis que se originou num cenário local, nacional, em língua portuguesa, para depois migrar para um cenário mais universal, para o mundo do leitor de língua inglesa. Não é à toa que Machado de Assis figura entre os cem melhores escritores mundiais de acordo com a lista elaborada por Harold Bloom e publicada em sua obra Genius: a mosaic of one hundred exemplary creative minds (2002).

43 ... [Machado de Assis ]... by his extraordinary talent as writer, by his profound literary dignity, by the unity of a life that was entirely devoted to the cult of intellectual beauty, and by the prestige exerted about him his work and by his personality, Machado de Assis succeeded, despite a nature that was averse to acclaim and little inclined to public appearance, in being considered and respected as the first among his country's men-of-letters [...]

${ }^{44}$ Como já mencionado, há uma quinta coletânea: The alienist and other stories of nineteenth-century Brazil. Trad. de John Charles Chasteen, Indianapolis: Hackett, 2013. 
Neste estudo buscou-se examinar o percurso de elaboração de quatro coletâneas de contos de Machado de Assis traduzidas para o inglês, sua organização, seleção, tradução e publicação no mundo anglo-americano em um período de mais de nove décadas. Foram abordados aspectos que dizem respeito aos critérios de seleção dos contos, aos tradutores, às editoras e aos metatextos que integram essas coletâneas, ou seja, um conjunto de fatores implícitos e explícitos envolvidos no processo tradutório que oferece ao leitor de língua inglesa alguns dos contos de Machado de Assis.

De maneira geral, pode-se destacar que essas quatro coletâneas foram formuladas e apresentadas de modo a respeitar rotinas de edição e preferências literárias, e ainda a atender as expectativas dos leitores anglo-americanos. Essas obras compostas pelas traduções dos contos e pelos textos externos que as suplementam tem as marcas que justificam esta configuração e de como devem ser consumidas no novo sistema literário. As políticas de edição da obra literária traduzida no Estados Unidos e Inglaterra deixam os leitores de língua inglesa confortáveis para receber a obra estrangeira, e os orientam na leitura de obras de um escritor brasileiro famoso, na forma de coletâneas de alguns de seus contos. De acordo com a crítica e os tradutores, essas coletâneas são compostas pelos contos mais conhecidos do grande escritor brasileiro, tirados de sua fase considerada mais madura. Os contos foram traduzidos por acadêmicos e profissionais de diferentes áreas do saber (Goldberg era jornalista, Grossman, era economista) ${ }^{45}$, mas principalmente por professores de literatura brasileira. Além disso, foram quase sempre publicados por editoras universitárias americanas e com o apoio de fundações (Rockefeller Foundation), empresas (Pan American sulphur Company) e, em edições posteriores, por editoras independentes (Peter Owen, Bloomsbury).

Além disso, conforme já explicitado, não somente motivações culturais, mas também políticas, econômicas, pessoais (Grossman) e filantrópicas (fundações e empresas que patrocinaram financeiramente as traduções) têm sido determinantes e concorrem para que os contos de Machado tenham sido escolhidos para serem traduzidos, e assim, perpetuarem a obra de Machado no mundo anglo-americano.

De acordo com o conteúdo dos metatextos, Machado chega aos países angloamericanos com seus contos traduzidos especialmente porque é do Brasil ("grande nação do hemisfério sul”) e integra o cânone literário do seu país de origem. Trata-se de pioneiro e primeiro escritor respeitado do país; é considerado um gênio, talentoso, ponto de referência na literatura de partida e comparável a autores europeus e americanos como James, Maupassant, Flaubert e Poe. O escritor brasileiro tem uma obra de alta qualidade literária apesar da grande dificuldade encontrada nos meios para sua produção, conforme destacado principalmente por Goldberg. Vê-se que sua produção ficcional tem grande prestígio, pois é re-editada, re-escrita/traduzida, reimpressa tanto no Brasil quanto no mundo anglo-americano, onde é veiculada há mais de nove décadas (1921-2013). Pode-se dizer que a obra de Machado já perdura e transita com desenvoltura em cenários culturalmente distintos. Os tradutores, as editoras, os leitores e a crítica apreciam as obras de Machado, elas têm aceitação e

\footnotetext{
${ }^{45}$ John Charles Chasteen, que organizou e traduziu a quinta coletânea de contos de Machado de Assis The alienist and other stories of nineteenth-century (2013) - é professor de História na University of North Carolina, Chapel Hill, Estados Unidos.

<http://www.hackettpublishing.com/latin-american-studies/the-alienist>
} 
credibilidade, e com isso estão perdurando, tendo uma pervida (Benjamim, 2001, ueberleben; fortleben).

Conforme mencionado anteriormente, e de acordo com Ria Vanderauwera (1985), Machado é traduzido para o inglês porque é um dos maiores e mais conhecidos escritores de seu país. A qualidade e o prestígio de sua obra também são aspectos enfatizados pelos tradutores nas introduções que elaboraram para suas coletâneas de contos. Conforme destaca Goldberg, quando menciona que Machado de Assis está entre os melhores escritores da literatura brasileira: "chief among the writers here represented [Brazilian] stands Joaquim Maria Machado de Assis (18391908)". De acordo com o texto da contracapa de Brazilian tales (Goldberg, 1921), Machado escreveu os melhores contos da literatura brasileira: the best known short stories in Brazilian literature, e ele é um dos mais renomados autores do Brasil outstanding authors [...] the great nation in the Southern Hemisphere.

As traduções publicadas conjugam os dois tipos de tradução apresentados por Vanderauwera e mencionados anteriormente. Além disso, confirma a questão do autor ser importante no seu sistema literário e as questões editoriais de acordo com o esperado pelo leitor de língua inglesa.

Os textos suplementares acrescidos às traduções fazem a mediação entre a obra e o leitor de língua inglesa. Eles acrescentam informações que orientam o leitor sobre o escritor brasileiro, contextualizam a obra e fazem um resumo da composição literária.

Os contos que foram incluídos nessas quatro coletâneas têm o importante papel de perpetuar, de manter viva, de garantir uma pervida para a obra de Machado via o processo da tradução. Eles foram reescritos em outra língua, a inglesa, que nesta era de mundo globalizado tem alcance mundial, e com isso se propagam e chegam não somente aos leitores que tem a língua inglesa como primeira língua mas também aos leitores que a transcendem e se utilizam da língua inglesa, considerada a língua franca de nosso tempo, universal, como meio de comunicação com povos de diferentes línguas e de instrução e fruição artística. O conteúdo da obra de Machado de Assis transcende os limites geográficos, pois ele escreve sobre o homem universal, capaz de ser lido e apreciado no mundo todo. E, como destaca Susan Sontag $(1990)^{46}$ em Afterlives: the case of Machado de Assis ("Vidas póstumas: o caso de Machado de Assis”), “com bastante tempo de existência, com bastante tempo após a morte do escritor, um grande livro encontra seu lugar de direito. E talvez alguns livros mereçam ser redescobertos sempre de novo.” Esse texto de Sontag, com pequenas modificações, é o prefácio do relançamento da tradução de "Memórias póstumas de Brás Cubas" de William L. Grossman, publicada pela editora Farrar, Straus \& Giroux (que adquiriu a Noonday Press) com o título de Epitaph of a Small Winner, em 1990.

Válmi Hatje-Faggion

hatjefaggion@yahoo.com

Universidade de Brasília

\footnotetext{
${ }^{46}$ with enough time, enough afterlife, a great book does find its rightful place. And perhaps some books deserve to be rediscovered again and again.”
} 


\section{Referências}

AMAZON. Website. Disponível em: <http://www.amazon.com>. Acesso em 12 de julho de 2013.

AMAZON. "O alienista e outras histórias de Século XIX Brasil”. [s.l.]: Amazon, 2013. Disponível em: <http://www.amazon.com/Alienist-Other-StoriesNineteenth-CenturyBrazil/dp/1603848525/> . Acesso em 29 de julho de 2013.

AMORIM, Galeno. Do Brasil para o mundo! In Fundação Biblioteca Nacional. Rio de Janeiro: Fundação Biblioteca Nacional, 2012. Disponível em: <http://www.bn.br/portal/index.jsp?nu_padrao_apresentacao=25\&nu_item_co nteudo=2120\&nu_pagina=1>. Acesso em 5 nov. 2012.

BASSNETT, Susan. From comparative literature to translation studies. In: . Comparative literature. Oxford e Cambridge: Blackwell, 1993. p. 138-161. - Translation studies in the 1990s. In: Clem Robyns (Org.) Translation and the (re) production of culture. Leuven: The CERA chair for translation, communication and cultures, 1994. p. 319-321.

. Translation studies. London e New York: Routledge, 1998 [1980].

. Researching translation studies: the case for doctoral studies. In: Peter Bush, Kirsten Malmkjaer (Org.) Rimbaud's rainbow: literary translation in higher education. Amsterdam: John Benjamins, 1998, p. 109-110.

. Estudos da tradução. Trad. de Vivina Figueiredo. Fundação Calouste Gulbenkian, Lisboa. 2003.

BENJAMIN, Walter. A tarefa-renúncia do tradutor. In: HEIDERMANN, Werner (org.). Antologia bilíngue - Clássicos da Teoria da Tradução, vol I: alemãoportuguês. Florianópolis: Núcleo de Tradução (NUT)/Universidade Federal de Santa Catarina (UFSC), 2001.

BLOOM, Harold. Genius: a mosaic of one hundred exemplary creative minds. New York: Warner, 2002.

BLOOMSBURY Publishing. New York: Bloomsbury Publishing Pic, 2012. Disponível em <http://www.bloomsbury.com>. Acesso em 12 jul. 2013.

BRAZILIAN AUTHORS ABROAD. Rio de Janeiro: Fundação Biblioteca Nacional, 1994.

CALDWELL, Helen. The Brazilian Othello of Machado de Assis: a study of Dom Casmurro. University of California Press, 1960.

. O Otelo brasileiro de Machado de Assis: um estudo de Dom Casmurro. Trad. Fábio Fonseca de Melo. São Paulo: Ateliê, 2002.

. Machado de Assis: The Brazilian master and his novels. University of California Press, 1970.

Conto. In: Machado de Assis: Obra completa. [s.l.]: Ministério da Educação, 2008. Disponível em: <http://machado.mec.gov.br/index.php?option= com_content\&view=article\&id=166: conto\&catid=34:obra-completa\&Ite mid=123>. Acesso em 20 jul. 2013.

DERRIDA, Jacques. L' oreille de l'autre. In: Claude Lvesque, Christie Mcdonald (Org.) Textes et débats. Montreal: VLB, 1982.

EVEN-ZOHAR, Itamar. Polysystems theory. Poetics Today, 1, 1-2, 1979, p. 287-310.

GARCIA, Rosália; Cybele ALLE; Amanda GARCIA; Ian ALEXANDER; Amanda Guizo ZAMPIERI. Traduções comentadas: Contos de Machado de Assis 
traduzidos. Revista Translatio, n.1, 2011. Porto Alegre: UFRGS. Disponível em: <http://seer.ufrgs.br/translatio/article/ view/36681/23748>. Acesso em 27 jan. 2013.

GENETTE, Gérard. Introduction. In:

. Paratexts. Cambridge: Cambridge University Press, 1997, p. 1-15.

GLEDSON, John. Translating Machado de Assis: "Dona Paula”“. Palestra proferida na Embaixada Brasileira em Londres dentro da Machado de Assis Week, 18 22 de junho de 2007. Disponível em: $<$ http://www.brazil.org.uk/events/machadodeassis.html>. Consultado em junho de 2008.

GOLDBERG, Isaac. Introdução. In: MACHADO DE ASSIS, Joaquim Maria. Brazilian tales. Trad. Isaac Goldberg (Org.). Boston: International Pocket Library, 1921. p. 9-31.

GROSSMAN, William L. Introdução. In: MACHADO DE ASSIS, Joaquim Maria. The psychiatrist and other stories. Trad. William L. Grossman e Helen Caldwell. Berkeley e Los Angeles: University of California Press, 1966, p. vii$\mathrm{x}$.

. Entrevista concedida a Otto Schneider. Jornal A manhã, Suplemento de domingo, em 11 de maio de 1952, p. 4.

ISHIMATSU, Lorie Chieko. Poetry of Machado de Assis. Albatros Hispanofilia, 1984.

Itaú Cultural. Assis, Machado de (1839 - 1908): Traduções e edições estrangeiras. In: Enciclopédia Itaú Cultural Literatura Brasileira. São Paulo: Itaú Cultural, 2008. Disponível em <http://www.itaucultural.org. br/aplicexternas/enciclopedia_lit/index.cfm?fuseaction=biografias_texto\&cd_ verbete $=4953 \&$ cd_item $=50>$. Acesso em 7 jul. 2013.

LAMBERT, Jose; VAN GORP, Hendrik. On describing translations. In: Theo Hermans (Org.). The manipulation of literature: studies in literary translation. New York: St. Martins, 1985, p. 42-53.

LANDERS, Clifford. E. Literary translation: a practical guide. Clevedon: Multilingual Matters, 2001.

LEFEVERE, André. Translating literature: practice and theory in a comparative literature context. New York: The Modern Language Association of America, 1992.

MACHADO DE ASSIS. A chapter of hats. London: Bloomsbury, 2009. Translated from the Portuguese by John Gledson. Disponível em $<$ http://www.bloomsbury.com/uk/a-chapter-of-hats-9780747596790/>. Acesso em 20 de julho de 2013.

. What Went on at the Baroness': A Tale with a Point. Tradução de Helen Caldwell. Google Books. [s.l.]: Google, 2012. Página web. Disponível em $<$ http://books.google.com.br/books/about/What

_Went_on_at_the_Baroness.html?id=dPWNOgAACAAJ\&redir_esc=y> Acesso em 7 jul. 2013.

. Brazilian tales. Trad. Isaac Goldberg (Org.). Boston: International Pocket Library, 1921.

. The psychiatrist and other stories. Trad. William L. Grossman e Helen Caldwell. Berkeley e Los Angeles: University of California Press, 1966. Também: Berkeley e Los Angeles: University of California Press, 1963; e London: Peter Owen, 1963. 
. What went on at the Baroness: a tale with a point. Trad. Helen Caldwell. Santa Monica, California: The Magpie Press, 1963.

. The devil's church and other stories. Trad. Jack Schmitt e Lorie Chieko Ishimatsu Austin e Londres: University of Texas Press, 1977.

. A chapter of hats and other stories. Trad. John Gledson. London, erlin, New York: Bloomsbury, 2008.

. The alienist and other stories of nineteenth-century Brazil. Trad. John Charles Chasteen. Indianapolis: Hackett, 2013.

. The mirror [O espelho]. Trad. Wilson Loria. Disponível no site. http://www.brazzil.com/pages/shjul95a.htm Acesso em 30 jan. 2006.

. The alienist. Trad. Alfred Mac Adam. Ilustração de Carroll Dunham. San Francisco: The Arion Press, 1998.

. Epitaph of a small winner. Trad. de William Grossman. New York: The Noonday Press, 1952.

. Posthumous reminiscences of Braz Cubas. Trad. de E. Percy Ellis. Rio de Janeiro: Instituto Nacional do Livro, 1955.

. The posthumous memoirs of Brás Cubas. Trad. de Gregory Rabassa. New York and Oxford: Oxford University Press, 1997.

. Epitaph of a small winner. Trad. de William Grossman. Introd. de Susan Sontag. New York: Farrar, Straus and Giroux, 1990.

. The heritage of Quincas Borba. Trad. de Clotilde Wilson. New York and London: W. H. Allen, 1954.

. Philosopher or dog? Trad. De Clotilde Wilson. New York: Farrar, Straus and Giroux, 1992.

. Philosopher or dog? Trad. de Clotilde Wilson. Bloomsbury: London, New York, Berlin, 1997.

. Quincas Borba. Trad. de Gregory Rabassa. New York and Oxford: Oxford University Press, 1998.

Machado de Assis: Obra completa. [s.l.]: Ministério da Educação, 2008. Disponível em: <http://machado.mec.gov.br>. Acesso em 12 mar 2013.

McCABE , Daniel. Sales figures Machado de Assis (mensagem pessoal). Mensagem recebida por<V.Hatje-Faggion@warwick.ac.uk> em 28 de jun. de 2001.

NEWMARK, Peter. A textbook of translation. New York, London: Prentice Hall, 1988.

PROJECT GUTENBERG. Free ebooks - Project Gutenberg. [s.l.]: Project Gutenberg, [s.d.]. Disponível em <http://www.gutenberg.org>. Acesso em 12 mar. 2013.

SBPT - Sociedade Brasileira de Planejamento de Transportes. Prêmio "William L. Grossman” - $7^{\circ}$ SET. [s.l.]: SBPT, 2012. Disponível em <http://www.transport-planning.org/2012/05/premio-william-l-grossman - set.html>. Acesso em 28 set. 2012.

SCHMITT, Jack; ISHIMATSU, Lorie. Introduction. In: MACHADO DE ASSIS, Joaquim Maria. The devil's church and other stories. Austin: University of Texas Press, 1977, p. ix-xiii.

Search result. In: Index Translationum. [s.l.] Unesco, [s.d.]. Disponível em $<$ http://www.unesco.org/xtrans/bsresult.aspx?a=machado+de+assis\&tr=schmit t>. Acesso em 27 de jan. 2013. 
SIMON, Sherry. Translation the will to knowledge: prefaces and Canadian literary politics. In: Susan Bassnett, Andre Lefevere (Org.). Translation history and Culture. London e New York: Cassell, 1990. p 110-117.

SONTAG, Susan. Afterlives: the case of Machado de Assis. New Yorker, May 7, 1990.

Introdução. In: MACHADO DE ASSIS, Joaquim Maria. Epitaph of a small winner. Trad. de William Grossman. New York: Farrar, Straus and Giroux, 1990. p. xix-xx.

The Devil's Church and Other Stories. University of Texas Press. Austin: UT, [s.d.]. Disponível em <http://utpress.utexas.edu/index.php/books/macdev \#sthash.5GdMHzJE.dpuf>. Acesso em 27 jan. 2013.

VANDERAUWERA, Ria. Dutch novels translated into English: the transformation of a "minority” literature. Amsterdam: Rodopi, 1985.

VV. AA. Brazilian Tales. [s.l.]: Project Gutemberg, 2007. Disponível em $<$ http://www.dominiopublico.gov.br/pesquisa/DetalheObraForm.do?select_act ion=\&co_obra=86813>. Acesso em 24 jun. 2013. 